\title{
Effect of community assembly and primary succession on the species-area relationship in disturbed ecosystems
}

\author{
Susan Carey, John Harte and Roger del Moral
}

\begin{abstract}
Carey, S., Harte, J. and del Moral, R. 2006. Effect of community assembly and primary succession on the species-area relationship in disturbed ecosystems. - Ecography 29: $866-872$.
\end{abstract}

\begin{abstract}
The species-area relationship (SAR) provides a cornerstone for ecological theory. Implicit in SAR studies is the assumption that SAR properties, especially SAR slopes, remain constant through time, even though the ecosystem characteristics that they encompass - the spatial distribution and abundance of species - change on seasonal to evolutionary time scales. Focusing on disturbed subalpine systems, we evaluated whether SAR properties are a function of stage of succession at Mount St. Helens, WA, and at Gothic, CO. We found that the SAR flattens and shifts upward as these systems mature. The decrease in SAR curvature at Mount St. Helens suggests a transition toward power-law SAR behavior with assembly. Overall, the observed changes in SAR properties raise questions about the appropriateness of applying contemporary SARs to predict future levels of species richness in disturbed or successional systems.
\end{abstract}

S.Carey (spalmer@nature.berkeley.edu),Dept Environmental Science, Policy, and Management, Univ. of California, Berkeley, CA 94720, USA. - J. Harte, Energy and Resources Group, Univ. of California, Berkeley, CA 94720, USA. - R. del Moral, Dept of Biology, Univ. of Washington, Seattle, WA 98195-5325, USA.

The species-area relationship (SAR), which describes the increase in the number of species found as the size of the sampling area increases, provides an important foundation in ecological theory (Rosenzweig 1995). Hypotheses proposed for the SAR pattern include the effect of 1) increasing sample size with increasing area [passive sampling hypothesis (Rosenzweig 1995)], 2) increasing habitat diversity and heterogeneity with increasing area [habitat diversity hypothesis (Preston 1960, Williams 1964)] and 3) changes in immigration and extinction rates with increasing area [dynamic equilibrium hypothesis (Brown 1971, MacArthur and Wilson 1967)]. The most commonly used form of the species-area equation is the power-law function, $\mathrm{S}=\mathrm{cA}^{\mathrm{z}}$, which can be $\log$-transformed to $\ln (\mathrm{S})=$ $\ln (\mathrm{c})+\mathrm{z} \times \ln (\mathrm{A})$, where $\mathrm{S}$ is the number of species observed in an area of size $\mathrm{A}$ and $\mathrm{z}$ and $\mathrm{c}$ are constants (Arrhenius 1921). Properties of the SAR are affected by the sampling scheme, spatial scale and types of organisms and habitats studied (Drakare et al. 2006).

Beyond quantifying species diversity patterns, the SAR has also been used to predict the impact of dynamic processes such as habitat loss and climate change on species richness (Kinzig and Harte 2000, Seabloom et al. 2002, Thomas et al. 2004). Implicit in these, and most other SAR studies, is the assumption that SAR properties remain temporally constant. In other words, the SAR measured today is assumed to represent the SAR under all future scenarios. However, the ecosystem characteristics that the SAR describes, namely the spatial distribution and abundance of species, vary seasonally and annually. Therefore, we might expect SAR properties to vary in accordance to

Accepted 31 August 2006 
seasonal peaks in reproduction and recruitment, annual variation in environmental factors, colonization and succession. The potential effect of time on SAR dynamics has emerged recently in the ecological literature (Adler and Lauenroth 2003, White 2004, Adler et al. 2005, White et al. 2006). While these studies have focused on understanding the effect of the length of sample time on the SAR and have argued for the use of a species-time-area relationship (STAR), we focus on a different aspect of time, namely the effect of when sampling is conducted. This explicit analysis of SAR properties from one point in time to another differs from the traditional SAR approach of combining data across the temporal extent of the study.

Here we focus on systems undergoing rapid assembly during primary succession. While studies have documented how species richness and relative abundance change through succession (Nicholson and Monk 1974, Sheil 2001, Wilson et al. 1996), the effect on SARs has not been well explored. Limiting our analysis to systems where species richness increases at the landscape level through time (i.e. species accumulation); there are several possible ways that SAR properties (e.g. slope (z), y-intercept [ $\ln (\mathrm{c})])$ may change between two sample periods in time. First, the SAR slope may remain constant while the yintercept increases, resulting in a simple shifting upward of the species-area curve. This is the null hypothesis that SARs describe the same functional relationship, defined by the slope value, regardless of community age. Second, the slope may increase. However, depending on the relative changes across spatial scales, the y-intercept may also increase, remain constant or decrease. Finally, the slope may decrease while the y-intercept increases.

In order to evaluate whether SAR properties depend on stage of succession, we assessed if and how SAR properties change in two subalpine systems. Subalpine ecosystems, estimated to cover $9 \%$ of the contiguous United States (Lugo et al. 1999), play an important role in ecosystem services such as water supply and regulation. In addition, because most biological activity is restricted by the length of the snow-free season, high elevation and latitude regions are expected to have relatively slow recovery rates from disturbance and to be relatively sensitive to the effects of climate change and global warming (Chapin et al. 1995). In this paper, we quantified SAR properties through succession for a 16-yr dataset from Mount St. Helens and a spacefor-time study on an earthflow near Gothic, CO. The space-for-time study allowed temporal trends to be approximated by assuming that different locations along a disturbance gradient represent different points in successional time.

\section{Material and methods}

\section{Mount St. Helens data set}

Mount St. Helens, located in the Cascade Range of southwestern Washington $\left(46^{\circ} 12^{\prime} \mathrm{N}, 122^{\circ} 11^{\prime} \mathrm{W}\right)$, experienced a massive lateral eruption in May 1980. This eruption destroyed the northern half of the cone and covered surrounding landscapes with pyroclastic flows (incandescent clouds of gas and solids), pumice deposits and lahars (mudflows) (Dale et al. 2005). One of us $(\mathrm{RdM})$ censused permanent grids, consisting of contiguous $10 \times 10 \mathrm{~m}\left(100 \mathrm{~m}^{2}\right)$ quadrats, in several habitats since 1980 . We analyzed data collected on two permanent grids differing in disturbance intensity: Abraham Plains $\left(40000 \mathrm{~m}^{2}\right)$ and Lahar $2\left(31700 \mathrm{~m}^{2}\right)$. The Abraham Plains grid is on a nearly level plain on the eastern side of Mount St. Helens between 1370 and $1382 \mathrm{~m}$ elevation. All vegetation was killed here due to searing blasts followed by a sweeping lahar and modest pumice deposits (del Moral and Wood 1993). The site remains sparsely covered and lacks common genera of the area (e.g. Lupinus, Juncus, Cistanthe) in many quadrats (del Moral et al. 2005). The Lahar 2 site is located on the southwestern side between 1440 and 1475 m elevation (del Moral 1998). All vegetation was removed by a lahar generated from rapidly melting ice. Common species at the site include Lupinus lepidus, Polygonum davisiae, Penstemon cardwellii, Eriogonum pyrolifolium var. coryphaeum and Abies sp. (del Moral and Ellis 2004).

The data used cover a $16-y r$ period at each site: 14 survey years between 1988 and 2003 at Abraham Plains and 10 survey years between 1987 and 2002 at Lahar 2. Vegetation surveys were conducted by inspecting each $100 \mathrm{~m}^{2}$ quadrat in mid-summer and recording species presence (Wood and del Moral 1988); species are vouchered in the Univ. of Washington herbarium. Minor modifications were made to the dataset in order to compare species presences between years in this analysis. We deleted very infrequent unknown species, which comprise $<1 \%$ of the total number of species presences at Abraham Plains and Lahar 2, and grouped firs (Abies lasiocarpa and Abies procera) as Abies sp. due to difficultly identifying seedlings to species. While the presence of mosses Polytrichum sp. and Racomitrium sp. was recorded, we restricted this analysis to vascular plants.

To eliminate differences in shape and size between grids, both grids were divided into contiguous nonoverlapping plots $(n=5$ at Abraham Plains, $n=4$ at Lahar 2). Each plot is $80 \times 80 \mathrm{~m}\left(6400 \mathrm{~m}^{2}\right)$ and consists of $8 \times 8$ quadrats (sixty-four quadrats). All analyses were conducted at the plot level, which was treated as a sample of the larger grid. Results presented are the average $( \pm \mathrm{SE})$ of plot values. This differs from other analyses of this dataset, which are conducted at the grid scale (del Moral and Wood 1993, del Moral 1998). 


\section{Gothic earthflow data set}

The Gothic earthflow, ca $1 \times 2 \mathrm{~km}$, is located five kilometers south of the Rocky Mountain Biological Laboratory in the Elk Mountains of Gunnison County, $\mathrm{CO}\left(38^{\circ} 56^{\prime} \mathrm{N}, 106^{\circ} 57^{\prime} \mathrm{W}, 2880 \mathrm{~m}\right)$. The surrounding area consists of subalpine perennial meadows containing a diverse mixture of woody shrubs (primarily Artemisia tridentata), forbs and graminoids, interspersed among aspen Populus tremuloides and spruce-fir forests (Picea engelmannii and Abies lasiocarpa). Information from local observations, climatic data and tree ring analysis suggests that the Gothic earthflow occurred in 1923, most likely due to heavy rainfall and seepage from an irrigation ditch (Langenheim 1956). By 2004, weathering and soil development had allowed plant colonization in all but the steepest portions of the earthflow; however, peak aerial vegetation cover remains low, decreasing toward the center of the earthflow. Soil translocation studies suggest that the limiting factor in colonization is the severe microclimate and soil conditions (Curtin 1994). These soil conditions may be slow to ameliorate because of the relatively large size of the earthflow, relatively short growing season and dominance by slowgrowing perennial species.

In 2004, we placed four non-overlapping $12 \times 30 \mathrm{~m}$ blocks across a horizontal transect from the middle to the outside of the earthflow. Three blocks were located within the earthflow and were hypothesized to represent three different stages of community assembly due to their different amounts of plant cover and distance to earthflow edge. The fourth block was located immediately adjacent to the earthflow. Aspect, slope and elevation were held constant across the blocks. Within each block, three non-overlapping $4 \times 4 \mathrm{~m}$ plots $\left(16 \mathrm{~m}^{2}\right)$ were randomly placed. Each earthflow plot was divided into sixty-four contiguous $0.5 \times 0.5 \mathrm{~m}\left(0.25 \mathrm{~m}^{2}\right)$ quadrats. Species presence/absence was recorded in each quadrat over the growing season by identifying all individuals to species when they flowered.

Assuming soil conditions limit colonization of the earthflow, soil properties may act as a proxy for successional stage. As a result, we measured several soil characteristics to test the hypothesis that the spatial gradient across the earthflow represents a temporal gradient in development. If this space-for-time substitution is valid, then we expect soil properties (e.g. organic matter, water holding capacity, etc.) to increase across the spatial gradient. All soil measurements were taken in the top $10 \mathrm{~cm}$ of soil; soil was collected using a stainless steel soil corer $(10 \mathrm{~cm}$ long, $1.7 \mathrm{~cm}$ in diameter). Soil texture was determined using the hydrometer method of Gee and Bauder (1986) ( $\mathrm{n}=1$ sample/plot). Water availability was approximated by gravimetric water content $[\mathrm{g}$ of water per $\mathrm{g}$ of dry soil $(<2 \mathrm{~mm})](\mathrm{n}=4$ samples/plot). Gravimetric water content was converted to volumetric water content (volume of water/volume of soil) by multiplying by soil bulk density. Soil bulk density (mass/volume of dry soil) was approximated by the equation developed by Adams (1973). Percent soil organic matter was estimated by weight loss on combustion ( $\mathrm{n}=4$ samples/plot).

\section{Species-area calculation through time}

We calculated the SAR for each plot and each year surveyed at Abraham Plains and Lahar 2 and for each Gothic plot, for a total of 70 (Abraham Plains), 40 (Lahar 2) and 12 (Gothic) SARs. Using a complete nested sampling plan, SARs were determined by calculating mean species richness across non-overlapping square and rectangular $(2 \times 1)$ quadrats of increasing area: 100, 200, 400, 800, 1600, 3200 and $6400 \mathrm{~m}^{2}$ (Mount St. Helens); 0.25, 0.5, 1, 2, 4, 8 and $16 \mathrm{~m}^{2}$ (Gothic). Only $2 \times 1$ rectangles were used because empirical and theoretical studies suggest that species richness depends on the shape of the area sampled (Condit et al. 1996, Kunin 1997, Harte et al. 1999). In addition, because richness might depend on the orientation of rectangular quadrats, rectangular richness was calculated by averaging the richness in non-overlapping horizontal and non-overlapping vertical rectangles. For each SAR, $\ln ($ mean species richness) was plotted as a function of $\ln$ (sample area). The data were then fit with a least squared linear regression line to form the log-transformed SAR $[\ln (S)=\ln (\mathrm{c})+\mathrm{z} \times \ln (\mathrm{A})]$. Slope $(\mathrm{z})$ and intercept $[\ln (\mathrm{c})]$ of the line were recorded.

The goodness of fit and curvature of the species-area data were quantified to assess whether the scaling of species richness with area becomes more power-law as the communities assemble. Here, goodness of fit refers to the adjusted $r^{2}$ value of the least-squared linear regression line through the log-transformed data, representing the proportion of the total variation in species richness that is accounted for by the linear regression line. Curvature, in its standard mathematical definition, is the rate of change in the angle of the curve $y=f(x)$ : $\kappa(x)=\frac{f^{\prime \prime}(x)}{\left(1+f^{\prime}(x)^{2}\right)^{3 / 2}}$. To quantify SAR curvature, we calculated the curvature of the quadratic regression line through the log-transformed species-area data at the geometric mean area value.

SAR properties (slope, intercept, $r^{2}$ and curvature) were plotted as a function of years since disturbance (Mount St. Helens) and block (Gothic). Temporallyaveraged species-area curves were also constructed for the Mount St. Helens data by averaging the SARs across all survey years. The average SARs were then compared to the SARs constructed for each survey year to illustrate the importance of temporal variability. SAR properties were also compared to the SAR properties observed on random landscapes (Coleman 1981). For 
each plot and year (Mount St. Helens) and plot (Gothic), we created 1000 random landscapes by randomizing the location of species presences. This randomization keeps total presences per species constant but changes the location of those presences (see Gotelli (2000) and Gotelli and Graves (1996) for discussion of problems associated with randomization of presences). SAR properties were then calculated for each random landscape and then averaged across the 1000 simulations. An increase in the difference between the observed and expected from random placement [(observed-expected)/ expected] as a function of succession suggests that the communities are becoming more different than random communities through time. In contrast, a decrease suggests that they are becoming less different than expected in random placement.

\section{Results}

At Mount St. Helens, species richness increased over time as species colonized the landscape (Fig. 1). Lahar 2 had greater initial richness than Abraham Plains due to the lower disturbance intensity experienced. However, Abraham Plains plot richness levels approached similar values to Lahar 2 by the end of the study period. The average species occupancy, average percent of cells occupied by a species, increased over time from 5.2 to $30.6 \%$ (Abraham Plains) and 36.4 to $63.2 \%$ (Lahar 2). A similar trend of increasing richness and percent cover with block was observed at the Gothic earthflow across the space-for-time gradient (Table 1). Gothic soil properties are also correlated with block (Table 1). Soil clay content, water content, and organic matter increased with block.

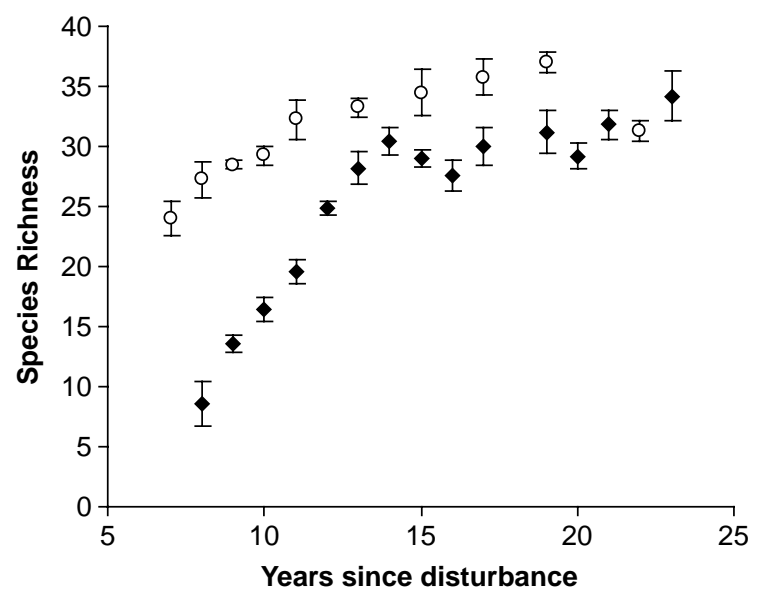

Fig. 1. Mount St. Helens species richness per plot $\left[6400 \mathrm{~m}^{2}\right]$ at Abraham Plains and Lahar 2 as a function of years since disturbance (1980). Black diamonds =Abraham Plains. White circles $=$ Lahar 2 . Each data point represents the average $( \pm \mathrm{SE}$ bars) of plots for a given year.
Through time the Abraham Plains and Lahar 2 SARs flatten and shift upward as the slope decreases and $y-$ intercept increases (Fig. 2). Over the study period, mean SAR slopes range from 0.24 to 0.72 at Abraham Plains and from 0.16 to 0.28 at Lahar 2 (Fig. 3a). The initial steep SAR slope at Abraham Plains results from low species richness $[8.6 \pm 1.9(1988)$ vs $34.2 \pm 2.1(2003)$ species per plot] with low average presences [5.2 \pm $0.5 \%$ (1988) vs $30.6 \pm 0.6 \%$ (2003) of cells occupied per plot per species present]. Mean y-intercepts $[\ln (\mathrm{c})]$ range from -4.17 to 1.34 at Abraham Plains and 0.82 to 2.03 at Lahar 2 [c: 0.0 to 3.8 species (Abraham Plains), 2.3 to 7.6 species (Lahar 2)] (Fig. 3b). While there is no trend in the $r^{2}$ values with time at Abraham Plains, $r^{2}$ values increase as a function of years since disturbance at Lahar 2 (Fig. 4a). Curvature decreases, approaches zero or no curvature, at both sites through succession (Fig. 4b). At Gothic, the SAR slope decreases and intercept increases as assembly progresses (Fig. 3c-d, 4c-d), similar to the Abraham Plains and Lahar 2 trends. However, there is no relationship between $r^{2}$ and curvature with block.

Pooling species data across the surveys into average SARs hid this temporal variation. Average SARs differed from the SARs calculated from only one year of data. At Abraham Plains, the average slope was $\bar{z}=$ 0.35 . At Lahar 2 , the average slope was $\bar{z}=0.20$, greater than most yearly slopes.

In addition, the random SAR had lower $r^{2}$ and greater curvature (more concave down) than the actual SARs. The difference between the observed and random $\mathrm{r}^{2}$ increased at Abraham Plains $(p=0.0122)$ but decreased at Lahar $2(\mathrm{p}=0.0052)$ as a function of years since disturbance (Mount St. Helens). The difference in curvature decreased at Abraham Plains $(p=0.0165)$ and had no change at Lahar $2(\mathrm{p}=0.6398)$.

\section{Discussion}

Extending previous analyses of primary succession, our results show that SAR properties change dramatically during succession. In general, the complete-nested SAR at Mount St. Helens and at Gothic flattens and shifts upward through time, with $z$ values falling in the range observed in other studies (Fridley et al. 2005, Drakare et al. 2006). These similarities exist despite differences in the area sampled at each site $\left[100-6400 \mathrm{~m}^{2}\right.$ (Mount St. Helens), $0.25-16 \mathrm{~m}^{2}$ (Gothic)]. Comparison to the SAR expected if species presences were random placed on the landscape shows that properties of these relationships become both more and less similar to the expected from a random distribution through time depending on the site and SAR property under consideration.

The similarity between sites suggests that these changes may reflect a universal trend as landscapes fill 
Table 1. Gothic vegetation and soil characteristics as a function of block (avg. \pm SE bars, $n=3$ plots/block). Blocks are ordered from the center to the outside of the earthflow with increasing number. Vegetation: 1) total species richness $16 \mathrm{~m}^{2}$ plot; 2) peak percent vegetative cover (29 June, 2004). Soil: 3) texture, percent clay; 4) percent soil organic matter (SOM); 5) soil volumetric water content (17 June 2004).

\begin{tabular}{lrrrr}
\hline & \multicolumn{3}{c}{ Block } \\
\cline { 3 - 5 } & \multicolumn{1}{c}{1} & 2 & 3 & 4 \\
\hline Vegetation & & & & \\
$\quad$ Species richness & $14.3 \pm 2.9$ & $21.3 \pm 2.9$ & $21.7 \pm 2.2$ & $30.0 \pm 1.2$ \\
$\quad$ Percent cover (\%) & $19.1 \pm 1.1$ & $36.5 \pm 5.2$ & $60.4 \pm 5.6$ & $84.1 \pm 3.1$ \\
Soil & $18.2 \pm 1.5$ & $23.9 \pm 0.9$ & $22.8 \pm 0.6$ & $39.3 \pm 3.3$ \\
$\quad$ Percent clay (\%) & $1.1 \pm 0.1$ & $2.2 \pm 0.6$ & $2.8 \pm 0.1$ & $7.9 \pm 0.8$ \\
$\quad$ Percent SOM (\%) & $9.3 \pm 1.3$ & $7.7 \pm 0.7$ & $8.5 \pm 0.8$ & $16.9 \pm 1.7$ \\
$\quad$ Vol. water content (\%) & & & & \\
\hline
\end{tabular}

in and are colonized. However, different processes may be driving these changes as the range of area sampled does not overlap between these sites (Turner and Tjorve 2005). If SAR properties, specifically slope and intercept, could be plotted as a function of successional stage, we might expect the values to collapse onto a common line. For example, in Fig. 3a, plotting the Mount St. Helens SAR properties as a function of average species richness shifts the Lahar 2 values to the right relative to Abraham Plains due to differences in successional stage and lines up the curves. This does not occur when results are plotted as a function of time because of site differences in the succession rate caused by differences in the magnitude of the disturbance.

Decreasing SAR slopes through colonization have been observed in other rapidly colonizing systems, such as ephemeral desert pools (Ward and Blaustein 1994) and successional plots on old fields (Leps and Stursa 1989). In addition, SAR slopes decreased as temporal sampling increased in eight assemblages (Adler et al. 2005). On much longer time scales (11-223 yr), however, increasing SAR slope values have been observed in

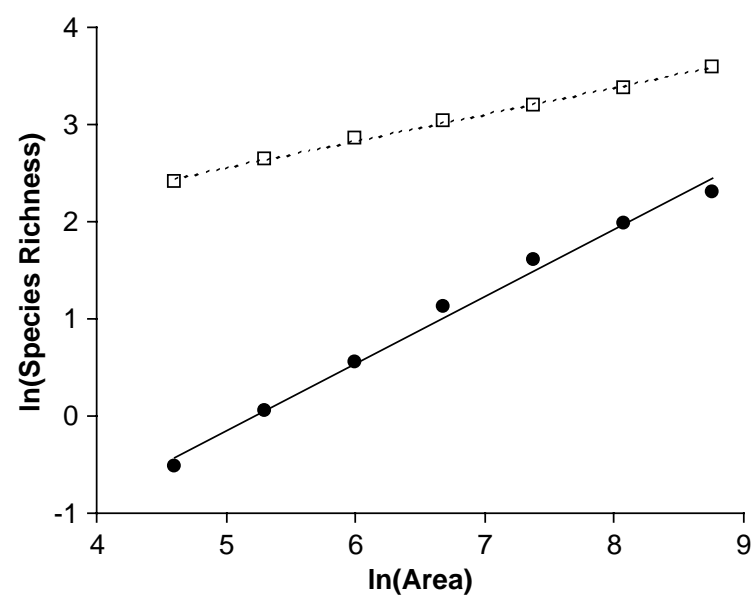

Fig. 2. 1988 and 2003 SAR for a sample plot: Abraham Plains for plot 4 . Black circles $=1988$. White squares $=2003$. $\ln \left(\mathrm{S}_{1988}\right)=$ $-3.60+0.69 \times \ln ($ Area $), \ln \left(\mathrm{S}_{2003}\right)=1.20+0.27 \times \ln ($ Area $)$. mixed deciduous forest patches (central Belgium) due to the slow accumulation of rare species with poor dispersing ability (Jacquemyn et al. 2001). In addition, we note that SAR slope values for spiders increase with assembly (Schoener and Spiller 2006); however, these SARs were constructed across islands of different sizes instead of areas nested within each other. A synthesis of such studies leads us to hypothesize that in rapidly assembling communities on severely disturbed landscapes, complete-nested SAR slopes will initially decline as species expand their range across the landscape in primary succession. During this period, some early colonists may be lost due to competitive exclusion. Eventually, depending on the strength of dispersal limitations, slopes may increase as more specialized species arrive. These changes may or may not be observed depending on the magnitude of changes in the spatial distribution and abundances of species. In fact, slopes may only be statistically dynamic during the initial stages of colonization and recovery from disturbance. However, the size of the window of dynamic behavior in time during recovery from disturbance may vary across taxonomic groups and ecosystems. In more stable systems not undergoing rapid successional change, SARs may remain constant through time.

We also hypothesize that important changes may occur in the power-law behavior of SARs with succession. While most of the species-area literature has emphasized power-law behavior (Rosenzweig 1995), there is often some degree of curvature in species-area data. The observed trend of decreasing curvature through time at Mount St. Helens suggests a transition toward power-law behavior as communities develop. This agrees with other studies that show an increase in $\mathrm{r}^{2}$ with colonization, such as on islands in Sweden (Rydin and Borgegard 1988). This complements Drakare et al.'s (2006) meta-analysis of the effect of sampling scheme, spatial scale and type of organism and habitat on goodness of fit and slope. Results from our simulations suggest that the changes observed here can not be conclusively attributed to these landscapes becoming more or less similar to randomly generated landscapes. 

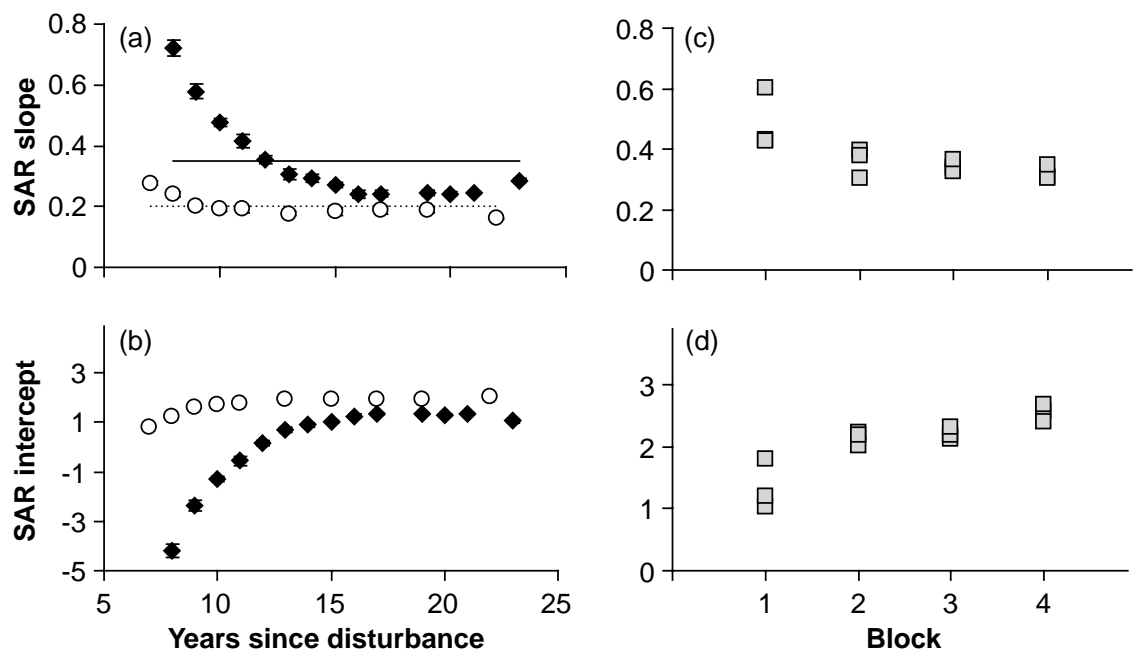

Fig. 3. SAR slope and intercept as a function of (a-b) years since disturbance (Abraham Plains and Lahar 2) and (c-d) block (Gothic). Black diamonds =Abraham Plains. White circles =Lahar 2. Gray squares =Gothic. Each data point represents the average ( \pm SE bars) of plots for a given year (Abraham Plains and Lahar 2 ) and a single plot (Gothic). Lines denote average slope values $\left(\overline{\mathrm{z}}_{A P}=0.35, \overline{\mathrm{z}}_{L 2}=0.20\right)$.

The observation of a dynamic SAR through colonization and succession illustrates that important temporal variation in SARs may exist. While this study focused on yearly variation (Mount St. Helens) in successional systems, variation may also occur on other time scales [e.g. seasonal (Peake and Quinn 1993)] and in nonsuccessional systems. For example, SAR properties may shift through time as species respond to factors such as changes in the external physical environment (e.g. amount and timing of rainfall, $\min / \max$ temperatures). Further exploration of temporal variation in SARs may
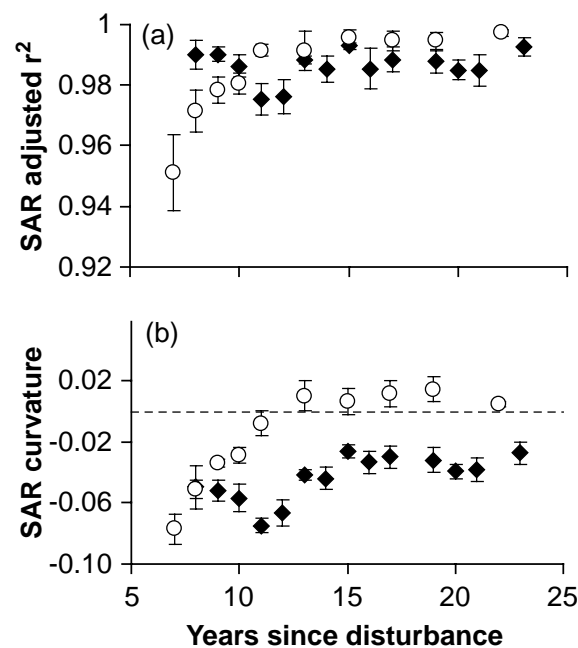

provide insight into potential processes and mechanisms driving the SAR, building on other attempts to understand the factors contributing to the SAR (e.g. Storch et al. 2003, Turner and Tjorve 2005). While this study demonstrates that the SAR measured in an undisturbed system should not be applied to a successional system and vice versa, it leaves unanswered whether or not predisturbance SARs will apply to future post-disturbance systems, once fully recovered. This will depend on whether or not the processes structuring the SAR are equivalent between the pre- and post-disturbance sys-

Fig. 4. SAR adjusted $\mathrm{r}^{2}$ and curvature as a function of (a-b) years since disturbance (Abraham Plains and Lahar 2) and (c-d) block (Gothic). Black diamonds =Abraham Plains. White circles $=$ Lahar 2. Gray squares $=$ Gothic. Each data point represents the average ( \pm SE bars) of plots for a given year (Abraham Plains and Lahar 2) and a single plot (Gothic). 
tems. For now, SAR studies that attempt to predict the effect of disturbance on species richness should consider the possibility that SAR properties may vary during the course of those events.

Acknowledgements - We thank J. Battles, C. Briggs, A. Ostling and $\mathrm{E}$. White for helpful comments on the manuscript and the staff of RMBL for their support. We also thank A. A. Berhe, M. Carey, E. Conlisk, K. Davis, M. Grant, J. Priest and M. Smith for their assistance with the Gothic field and lab work. This work was supported by grants from the National Science Foundation. The Mount St. Helens data was collected under National Science Foundation LTREB Grants no. 0089704, 9406957 and 8906544.

\section{References}

Adams, W. A. 1973. The effect of organic matter on the bulk and true densities of some uncultivated podzolic soils. - J. Soil Sci. 24: 10-17.

Adler, P. B. and Lauenroth, W. 2003. The power of time: spatiotemporal scaling of species diversity. - Ecol. Lett. 6 : $749-756$.

Adler, P. B. et al. 2005. Evidence for a general species-time-area relationship. - Ecology 86: 2032-2039.

Arrhenius, O. 1921. Species and area. - J. Ecol. 9: 95-99.

Brown, J. H. 1971. Mammals on mountaintops-nonequilibrium insular biogeography. - Am. Nat. 105: 467-478.

Chapin, F. S. III et al. 1995. Responses of arctic tundra to experimental and observed changes in climate. - Ecology 76: $694-711$.

Coleman, B. D. 1981. On random placement and species-area relations. - Math. Biosci. 54: 191-215.

Condit, R. et al. 1996. Species-area and species-individual relationships for tropical trees: a comparison of three 50ha plots. - J. Ecol. 84: 549-562.

Curtin, C. G. 1994. The Gothic earthflow revisited: a chronosequence examination of colonization on a subalpine earthflow. - Vegetatio 111: 137-147.

Dale, V. H. et al. (eds) 2005. Ecological responses to the 1980 eruption of Mount St. Helens. - Springer and Business Media.

del Moral, R. 1998. Early succession on lahars spawned by Mount St. Helens. - Am. J. Bot. 85: 820-828.

del Moral, R. and Wood, D. M. 1993. Early primary succession on a barren volcanic plain at Mount St. Helens, Washington. - Am. J. Bot. 80: 981-991.

del Moral, R. and Ellis, E. E. 2004. Gradients in compositional variation on lahars, Mount St. Helens, Washington, USA. - Plant Ecol. 175: 273-286.

del Moral, R. et al. 2005. Proximity, microsites, and biotic interactions during early succession. - In: Dale, V. H. et al. (eds), Ecological responses to the 1980 eruption of Mount St. Helens. Springer and Business Media, pp. 93-109.

Drakare, S. et al. 2006. The imprint of the geographical, evolutionary and ecological context on species-area relationships. - Ecol. Lett. 9: 215-227.

Fridley, J. D. et al. 2005. Connecting fine- and broad-scale species-area relationships of southeastern U.S. flora. - Ecology 86: 1172-1177.

Gee, G. W. and Bauder, J. W. 1986. Particle-size analysis. - In: Klute, A. (ed.), Methods of soil analysis, Part 1. Physical and mineralogical methods. American Society of Agronomy, pp. $383-411$.

Gotelli, N. J. 2000. Null model analysis of species co-occurrence patterns. - Ecology 81: 2606-2621.

Gotelli, N. J. and Graves, G. R. 1996. Null models in ecology. - Smithsonian Inst.
Harte, J. et al. 1999. Estimating species-area relationships from plot to landscape scale using species spatial-turnover data. - Oikos 86: 45-54.

Jacquemyn, H. et al. 2001. Forest plant species richness in small, fragmented mixed deciduous forest patches: the role of area, time and dispersal limitation. - J. Biogeogr. 28: 801-812.

Kinzig, A. P. and Harte, J. 2000. Implications of endemics-area relationships for estimates of species extinctions. - Ecology 81: $3305-3311$.

Kunin, W. E. 1997. Sample shape, spatial scale and species counts: implications for reserve design. - Biol. Conserv. 82: 369-377.

Langenheim, J. H. 1956. Plant succession on a subalpine earthflow in Colorado. - Ecology 37: 301-317.

Leps, J. and Stursa, J. 1989. Species-area curve, life-history strategies, and succession: a field test of relationships. - Vegetatio 83: 249-257.

Lugo, A. E. et al. 1999. The Holdridge life zones of the conterminous United States in relation to ecosystem mapping. - J. Biogeogr. 26: 1025-1038.

MacArthur, R. and Wilson, E. O. 1967. The theory of island biogeography. - Princeton Univ. Press.

Nicholson, S. A. and Monk, C. D. 1974. Plant species diversity in old-field succession on the Georgia Piedmont. - Ecology 55: $1075-1085$.

Peake, A. J. and Quinn, G. P. 1993. Temporal variation in species-area curves for invertebrates in clumps of an intertidal mussel. - Ecography 16: 269-277.

Preston, F. W. 1960. Time and space and the variation of species. - Ecology 41: 611-627.

Rosenzweig, M. L. 1995. Species diversity in space and time. - Cambridge Univ. Press.

Rydin, H. and Borgegard, S.-O. 1988. Plant species richness on islands over a century of primary succession Lake Hjalmaren Sweden. - Ecology 69: 916-927.

Schoener, T. W. and Spiller, D. A. 2006. Nonsynchronous recovery of community characteristics in island spiders after a catastrophic hurricane. - Proc. Nat. Acad. Sci. 103: 2220 2225.

Seabloom, E. W. et al. 2002. Extinction rates under nonrandom patterns of habitat loss. - Proc. Nat. Acad. Sci. 99: 1122911234.

Sheil, D. 2001. Long-term observations of rain forest succession, tree diversity and responses to disturbance. - Plant Ecol. 155: 183-199.

Storch, D. et al. 2003. Geometry of the species-area relationship in central European birds: testing the mechanism. - J. Anim. Ecol. 72: 509-519.

Thomas, C. D. et al. 2004. Extinction risk from climate change. - Nature 427: 145-148.

Turner, W. R. and Tjorve, E. 2005. Scale-dependence in speciesarea relationships. - Ecography 28: $721-730$.

Ward, D. and Blaustein, L. 1994. The overriding influence of flash floods on species-area curves in ephemeral Negev Desert pools-a consideration of the value of island biogeography theory. - J. Biogeogr. 21: 595-603.

White, E. P. 2004. Two-phase species-time relationships in North American land birds. - Ecol. Lett. 7: 329-336.

White, E. P. et al. 2006. A comparison of the species-time relationship across ecosystems and taxonomic groups. - Oikos 112: 185-195.

Williams, C. B. 1964. Patterns in the balance of nature and related problems in quantitative ecology. - Academic Press.

Wilson, J. B. et al. 1996. Are there assembly rules for plant species abundance? An investigation in relation to soil resources and successional trends. - J. Ecol. 84: 527-538.

Wood, D. M. and del Moral, R. 1988. Colonizing plants on the Pumice Plains, Mount St. Helens, Washington, USA. - Am. J. Bot. 75: 1228-1237.

Subject Editor: Helmut Hillebrand. 